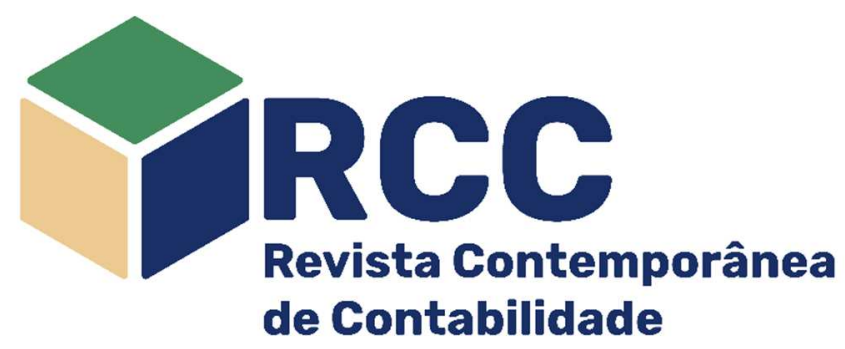

\title{
Mulheres CEO (Chief Executive Officer) e CFO (Chief Financial Officer): influência da presença feminina na qualidade dos accruals
}

\author{
Women as CEO (Chief Executive Officer) and CFO (Chief Financial Officer): influence of female \\ presence on the quality of accruals
}

\section{Mujeres como CEO (Chief Executive Officer) y CFO (Chief Financial Officer): influencia de la presencia femenina en la calidad de las acumulaciones}

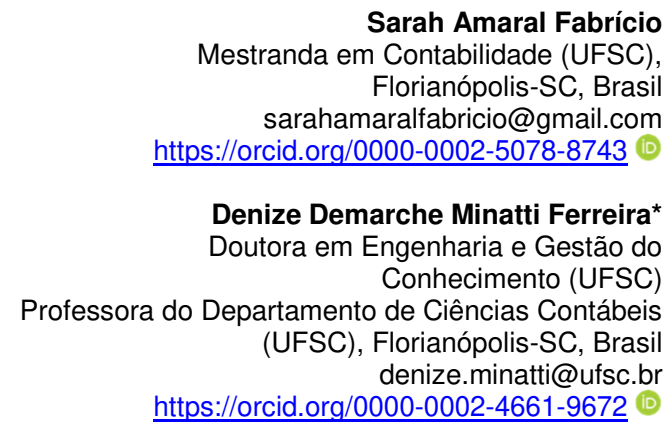

Campus Universitário Reitor João David Ferreira Endereço do contato principal para correspondência Doutor em Controladoria e Contabilidade (USP) alex.mussoi@ufsc.br https://orcid.org/0000-0003-3389-9713 (10)

Endereço do contato principal para correspondência
Kátia Dalcero Doutoranda em Contabilidade (UFSC) Florianópolis-SC, Brasil katiadalcero13@gmail.com https://orcid.org/0000-0002-2123-3343 (1)

Alex Mussoi Ribeiro Professor do Departamento de Ciências Contábeis (UFSC),

Florianópolis-SC, Brasil

\section{Resumo}

A presença feminina em cargos de diretoria executiva, gerência de alto escalão e nos conselhos tem apontado influência significativa na diminuição dos accruals discricionários das companhias. O estudo parte dos pressupostos evidenciados nas hipóteses $\mathrm{H} 1 \mathrm{a}$ e $\mathrm{H} 1 \mathrm{~b}$ de que empresas com $\mathrm{CEO}$ e/ou CFO do gênero feminino possuem menos accruals discricionários e, assim, uma maior qualidade dos lucros. $\mathrm{O}$ modelo empírico foi aplicado numa amostra de 170 empresas não financeiras listadas na B3 S/A - Brasil, Bolsa, Balcão de 2013 a 2018. Os resultados rejeitam a H1a. Já os achados não rejeitam H1b, ou seja, foi encontrada influência significativa do CFO do gênero feminino com a diminuição da discricionariedade dos accruals que resulta em uma melhor qualidade dos lucros. A pesquisa ainda observou o total de mulheres como CEOs e CFOs, sendo 25 (2,68\%) e 72 (7,73\%), respectivamente, totalizando 97 mulheres em ambos os cargos.

Palavras-chave: Presença Feminina; CEO; CFO; Accruals; Qualidade dos Lucros

\section{Abstract}

The presence of women in the positions of executive board, senior management and councils has pointed to a significant influence in the reduction of company discretionary accruals. The study started from the assumptions evidenced in hypotheses $\mathrm{H} 1 \mathrm{a}$ and $\mathrm{H} 1 \mathrm{~b}$ that companies with female $\mathrm{CEO}$ and/or CFO have less discretionary accruals and so, a higher earnings quality. The empirical model was applied to a sample of 170 non-financial companies listed in B3 S/A - Brasil, Bolsa, Balcão from 2013 to 2018. The results reject H1a. The findings do not reject $\mathrm{H} 1 \mathrm{~b}$, that is, there was a significant influence of the female CEO with the decrease in the discretion of accruals, which results in better earnings quality. The survey also recorded the total number of women as CEOs and CFOs, with 25 (2.68\%) and 72 (7.73\%), respectively, totaling 97 women in both positions.

Keywords: Female Presence; CEO; CFO; Accruals; Earnings Quality 


\section{Resumen}

La presencia de mujeres en puestos de dirección, alta dirección y en los consejos ha apuntado a una influencia significativa en la reducción de los devengos discrecionales de las empresas. El estudio parte de los supuestos evidenciados en las hipótesis $\mathrm{H} 1 \mathrm{a}$ y $\mathrm{H} 1 \mathrm{~b}$ de que las empresas con directora ejecutiva y / o directora financiera mujer tienen menos devengos discrecionales y, por tanto, una mayor calidad de beneficios. El modelo empírico se aplicó a una muestra de 170 empresas no financieras que cotizan en B3 S/A - Brasil, Bolsa, Balcão de 2013 a 2018. Los resultados rechazan H1a. Los hallazgos no rechazan H1b, es decir, hubo una influencia significativa de la directora financiera femenina con la disminución en la discreción de las acumulaciones, lo que se traduce en una mejor calidad de las ganancias. La encuesta también observó el número total de mujeres como CEO y CFO, con $25(2,68 \%)$ y $72(7,73 \%)$, respectivamente, para un total de 97 mujeres en ambos puestos.

Palabras clave: Presencia Feminina; CEO; CFO; Accruals; Calidad de Lucros

\section{Introdução}

As investigações sobre a presença feminina estão mais frequentes nos estudos das áreas da contabilidade, especialmente no que tange as relações à tomada de decisão de investidores e administradores. No entanto, apesar das iniciativas que estimulam o aumento da representação das mulheres em posições de maior responsabilidade, seu progresso continua gradual e lento.

As desigualdades históricas em termos ocupacionais persistem, sobretudo se mencionar que as mulheres constituem minoria nas ocupações de status, como, por exemplo, cargos de alta gerência e posições executivas, como Chief Executive Officer (CEO), Chief Financial Officer (CFO), Chief Operations Officer (COO), além dos boards de diretores (Hryniewicz \& Vianna, 2018).

O censo realizado pela Catalyst (2009) apontou que em 2006 e 2007, respectivamente, o percentual de mulheres foi de $14,8 \%$ e $14,6 \%$ nos conselhos das empresas da Fortune 500. E, em 2008 e 2009, elas representavam $15,2 \%$ dos assentos no conselho de administração, com $90 \%$ dessas empresas tendo pelo menos uma representante do sexo feminino em seus conselhos corporativos, enquanto $20 \%$, mais de três delas (Catalyst, 2009).

Em 2009, no Canadá, as mulheres ocupavam 14\% dos assentos no conselho das empresas Fortune 500 e, em 41,9\% das empresas não há mulheres no conselho. Esse percentual chega a 39,5\% em 2011. Além disso, em 2009, 19,3\% das empresas da Fortune 500 detinham 25\% ou mais de mulheres e, em 2011, apenas 21\% (Catalyst, 2019).

No que diz respeito a França, o aumento percentual de conselheiras na administração das empresas da Cotation Assistée en Continu (CAC 40) foi de 16,5\% em 2010 e 20,6\% em 2011 (Natividad, 2011). Além disso, a promulgação da Lei $n^{\circ}$ 2011-103 de 27/01/2011 que implica na representação igualitária de homens e mulheres no conselho de administração e no conselho fiscal e igualdade profissional - incentivou as empresas francesas a nomear mais mulheres em seus conselhos (Hili \& Affes, 2012). França, Noruega e Espanha apresentam obrigações legais para que as mulheres ocupem no mínimo $40 \%$ do quadro de diretores do conselho de administração. Assim como na Austrália que, desde 2010 há campanhas para que empresas tenham 30\% de mulheres nos assentos dos conselhos (Fernandes et al., 2015).

O relatório da Grant Thornton (2020) aponta que nos últimos dezesseis anos houve diferença na proporção de mulheres que ocupam cargos de liderança dentre as quase 5.000 empresas avaliadas pela International Business Report (IBR), atingindo proporção global de $29 \%$. Quanto aos dados referentes à América Latina, a proporção de mulheres em cargos de liderança é de $33 \%$ maior que no mundo (Grant Thornton, 2020) e, há ainda evidências de que a fração delas nos cargos de CEO/CFO no ano de 2020 globalmente corresponda a $20 \%$ e $30 \%$, respectivamente.

A representatividade feminina é maior na Bélgica (33\%), Finlândia (40\%), Islândia (40\%), Israel (50\%), Itália (33\%), Québec - Canadá (50\%) e Quênia (33\%) que implementaram legislações impulsionadoras para cotas de gênero no conselho de administração (Terjesen et al., 2015). Os autores afirmam que em outras nações como Austrália, Áustria, Dinamarca, Alemanha, Irlanda, Luxemburgo, Malawi, Malásia, Países Baixos, Nigéria, Polônia, África do Sul, Suécia, Reino Unido e Estados Unidos há códigos de boas práticas de governança que recomendam diversidade de gênero nos conselhos (Terjesen et al., 2015).

A tendência de equidade de gênero está chegando lentamente no Brasil, o Projeto de Lei 112/2010 tramita no Senado Federal e estabelece que os conselhos de administração das empresas públicas, sociedades de economia mista e aquelas controladas pela União apresentem um percentual mínimo de $40 \%$ de mulheres em sua composição até 2022 (Alves, 2010). Porém, a realidade é distante desse projeto, segundo o Instituto Brasileiro de Governança Corporativa (IBGC) (2019) em 508 empresas listadas pela Bovespa nos diferentes segmentos, 197 contam com pelo menos uma mulher no conselho de administração (38,78\%) e 165 (32,48\%) quando se considera apenas a participação de conselheiras efetivas.

No que tange à presença de mulheres em cargos de CEO, a imprensa descreve escassez de liderança feminina no mundo dos negócios. Em 2006, o New York Times informou que nove dos CEOs das empresas da Fortune 500 eram mulheres, correspondendo menos de $2 \%$ do total (Bartz \& Creswell, 2006). 
Estudos de contabilidade e finanças apontam que um CFO tem impacto direto nos relatórios financeiros (Barua et al., 2010) e nas decisões de gerenciamento de accruals das empresas (Feng et al., 2011; Jiang; Petroni; Wang, 2010; Mian, 2001) e que, em geral, as mulheres são mais avessas ao risco e mais conservadoras do que os homens na tomada de decisões financeiras (Liu et al., 2016).

Uma vertente mais recente da literatura aponta evidências de que a presença feminina em cargos de alta gestão: reduz a probabilidade de fraude (Capezio \& Mavisakalyan, 2016; Cumming et al. 2015) e melhora a qualidade dos ganhos (Srinidhi et al. 2011; Zalata et al. 2018). Da mesma forma, sugerem que as diretoras executivas estão associadas a relatórios financeiros mais conservadores (Ho et al. 2015; Palvia et al. 2015), maior qualidade contábil (Barua et al. 2010) e redução de relatórios financeiros fraudulentos (Sun et al. 2019).

A presença feminina na diretoria aprimora a qualidade das discussões e aumenta a capacidade de melhor supervisão das divulgações das informações financeiras e dos relatórios contábeis das empresas (Gul et al., 2011). Os autores afirmam ainda que o fato pode afetar a informatividade do preço das ações uma vez que diretorias e conselhos com presença feminina apresentam melhores discussões de questões ignoradas pelas diretorias masculinas e, portanto a comunicação se torna mais eficaz entre os membros da diretoria (Ray, 2005), o que permite divulgações mais fidedignas das informações e dos relatórios financeiros, ao influenciar diretamente a informatividade do preço das ações e a diminuição dos custos de informações para gestores e investidores (Durnev et al., 2004).

Além disso, a presença feminina nos conselhos administrativos, fiscais, de auditoria e governança aumenta o poder de fiscalização desses, o que exige maior responsabilidade dos gerentes em relação ao desempenho das empresas (Gul et al., 2011). Ainda é relatado que a inclusão de mulheres em cargos de alta gerência na empresa está positivamente associado à qualidade dos lucros (Krishnan \& Parsons, 2008).

Ismail, Shafe e Ismail (2020) salientam a falta de estudos da relação da presença feminina em cargos de CEOs/CFOs em países em desenvolvimento e de economia emergente. Assim, este estudo busca investigar esta lacuna de pesquisa ao contribuir com a literatura, por meio da investigação da relação da influência da presença feminina nos cargos de CEO e CFO na qualidade dos accruals, das empresas brasileiras que possuem ações negociadas na B3 S/A - Brasil, Bolsa, Balcão.

A partir destes fatos, o presente estudo levanta como problema de pesquisa: Qual a influência da presença feminina nos cargos de CFOs e CEOs na qualidade dos accruals? E, deste modo tem por objetivo verificar a influência da presença feminina nos cargos de CFOs e CEOs na qualidade dos accruals por meio de inferências estatísticas.

O estudo busca contribuir com a literatura ao discutir sobre o efeito da presença feminina na melhoria da qualidade dos accruals, sendo este, um dos diferenciais da pesquisa. Além disso, busca demonstrar para as empresas e órgãos de regulação a importância de as organizações possuir membros do gênero feminino em cargos de alto escalão para a melhoria da qualidade dos accruals.

A motivação do estudo se dá pelo aumento (voluntário ou não) da presença feminina na gestão de empresas brasileiras nos últimos anos e necessidade de se compreender a dinâmica disto na qualidade dos relatórios corporativos. Portanto, o estudo busca preencher a lacuna de pesquisa sobre a relação da presença feminina dos cargos de CEO e CFO com a qualidade dos lucros.

$\mathrm{O}$ artigo ainda contribui de forma indireta para a literatura acerca de mulheres em cargos de alta gerência e os diversos efeitos positivos que elas possam trazer para as empresas. Parafraseando Francesca Lagerberg, líder global de network capabilities da Grant Thornton International Ltda: Por que ter mais mulheres em cargos de liderança é importante? Pelo valor obtido por meio da diversidade de pensamentos, pois se a liderança de uma empresa é formada de grupos de pessoas com origem, cultura e gênero semelhantes se perde algo no mercado. Logo, é preciso diversidade para observar o mundo com visão mais ampla o que provavelmente reflete melhor seus clientes e os problemas e oportunidades com que se deparam (Grand Thornton, 2020).

Consequentemente, a presente pesquisa pode auxiliar pesquisadores em estudos futuros, como uma forma de ampliar a compreensão do impacto das mulheres CEOs e CFOs no contexto da contabilidade, especificamente em relatórios financeiros.

\section{Referencial Teórico}

\subsection{Informações sobre a qualidade dos lucros e preços das ações}

Loomis (1999) argumenta que o gerenciamento de resultados é visto pelos CEOs como uma ferramenta para garantir que as empresas atendam às expectativas de lucros. Loomis (1999) relata ainda que para o presidente da Securities and Exchange Commission (SEC), relatórios falsificados e registros falsos são um problema comum e existem em grandes extensões, esperando apenas serem revelados.

Para Chan et al. (2006), a mensuração dos accruals contábeis constitui um tema que tem recebido atenção nos últimos anos haja vista a importância dessa medida como possível indicador da qualidade do lucro e da avaliação patrimonial de uma empresa. De acordo, com Dechow e Dichev (2002), os accruals possuem papel de mudar e ajustar os fluxos de caixa ao longo do tempo e, com os lucros ajustados podem 
facilitar a medição do desempenho das empresas. Porém, os autores salientam ainda que os accruals estão propensos a uma série de julgamentos contábeis e de suposições de estimativas futuras de fluxos de caixa.

Conforme Lustosa et al. (2010), altos accruals associados a altos lucros (reconhecido com lucros de baixa qualidade) podem ter origem na antecipação de receitas e postergação de despesas, que consequentemente, aumenta as contas de "recebíveis" e "contas a pagar", o que resultaria em um fluxo de caixa corrente reduzido. Assim, a avaliação de fluxos de caixas futuros com base nos valores isolados de lucro e fluxo de caixa corrente resultaria em prognóstico errado de seus valores.

Os julgamentos e as suposições de fluxos de caixa futuros facilitam o gerenciamento de resultados pelos gestores podendo acontecer por meio de duas formas: gerenciamento baseado em accruals e gerenciamento baseado em atividades reais. Healy e Wahlen (1999) apontam que o gerenciamento de resultados baseado em accruals ocorre quando os gerentes aplicam o julgamento nos relatórios financeiros e na estruturação de transações para alterar os relatórios financeiros para burlar as partes interessadas no desempenho econômico da empresa ou influenciar os resultados contratuais que dependem dos números contábeis.

Os gerentes podem se envolver ativamente no gerenciamento de resultados, porque os lucros contábeis relatados geralmente afetam sua remuneração. De acordo com a Teoria da Agência, é mais provável que os gerentes (agente) procurem o interesse próprio em vez do interesse dos acionistas (principal). Assim, para reduzir o conflito de agência, os acionistas fornecem planos de incentivo, tais como, vincular o lucro contábil a compensações dos gerentes. No entanto, os gerentes podem manipular as informações contábeis usando accruals discricionários para aumentar ou diminuir os resultados no final do período (Thiruvadi \& Huang, 2011).

\subsection{Influência do gênero na tomada de decisão e na qualidade dos lucros}

Os estudos na área de contabilidade financeira demonstram que o CFO impacta na elaboração dos demonstrativos, principalmente no gerenciamento de resultados, por meio das escolhas contábeis. A adesão às normas IFRS (International Financial Reporting Standards) e o aumento da subjetividade das escolhas contábeis no julgamento da maneira de mensuração dos itens do patrimônio da entidade refletem diretamente no lucro da empresa, e contribuem para o gerenciamento dos resultados da entidade (Favoretto et al., 2017).

Ray (2005) aponta que a presença feminina nos conselhos permite que os diretores sejam mais criteriosos, com perspectivas diferentes e muitas vezes conflitantes. Ainda segundo o autor, os conselhos com maior diversidade são menos propensos a assumir posições extremas, pois contribuem na conscientização da empresa sobre questões éticas e de responsabilidade social, se concentrando na criação de valor, mostrando maior sensibilidade à oportunidades e ameaças às empresas. A presença de mulheres nas diretorias e conselhos auxilia também na melhoria da divulgação das informações contábeis para os stakeholders (Gul et al., 2011).

Além disso, há diferença em relação ao estilo de liderança entre homens e mulheres, enquanto os homens têm estilo mais agressivo, baseado no comando e na conformidade, as mulheres apresentam estilo caracterizado pela confiança baseado na cooperação (Klenke, 2003; Nierdele \& Vesterlund, 2007).

Os conselhos diversificados onde exista mais cooperação nas trocas de informações entre os diretores e funcionários auxiliam em discussões mais profundas entre os membros (Gul et al., 2011). Ainda, os mesmos autores afirmam que uma diretoria mais diversificada aumenta a probabilidade da criação de um ambiente de informação mais rico, reduzindo custos com coleta das informações principalmente de empresas menores.

Diante do cenário atual, se percebem exigências frequentes para que as organizações se posicionem em relação a presença feminina na composição de seus quadros e, antes mesmo da emergência da questão, estudos direcionados ao estudo do gênero, tanto em âmbito nacional quanto internacional apontam uma proliferação de pesquisas relacionadas ao tema (Tabela 1).

A literatura internacional apresenta número maior de pesquisas sobre a relação entre a presença feminina e a qualidade da informação contábil. Gul et al. (2011) verificaram a influência do gênero na qualidade da auditoria, Barua et al. (2010) e Liu; Wei e Xie (2016) investigaram o efeito da presença feminina na qualidade dos accruals, e ainda Gul et al. (2011) observaram a influência desta na melhoria da informatividade do preço das ações.

Barua et al. (2010) examinaram o efeito do gênero do CFO e do CEO na qualidade dos accruals. Os resultados demonstraram quando o CFO e/ou CEO é do gênero feminino os accruals possuem menos discricionariedade. Nessa mesma perspectiva, Liu et al. (2016) analisaram os efeitos do gênero do CFO no gerenciamento de resultados das empresas chinesas entre 1999 a 2011. Os resultados apontaram que os CFOs do gênero feminino estão menos propensos ao gerenciamento de resultado em comparação ao do gênero masculino, pelas mulheres serem mais conservadoras na análise dos investimentos.

Gul et al. (2011) constataram uma associação positiva entre a presença feminina dos conselhos com a informatividade sobre os preços das ações. Para os autores, a melhoria das divulgações públicas das informações e dos relatórios financeiros auxilia na diminuição dos custos informacionais para os stakeholders. 
Tabela 1:

Estudos nacionais relacionados a gênero dos CFOs e CEOs

\begin{tabular}{|c|c|c|}
\hline Autor(es)/Data & Objetivo & $\begin{array}{l}\text { Principais Resultados } \\
\end{array}$ \\
\hline $\begin{array}{c}\text { Silva e Margem } \\
\qquad(2015)\end{array}$ & $\begin{array}{l}\text { Identificar se a presença de mulheres no } \\
\text { conselho de administração e diretoria } \\
\text { gera impacto no valor/desempenho das } \\
\text { empresas brasileiras de capital aberto. }\end{array}$ & $\begin{array}{l}\text { Não existe relação estatisticamente significativa entre a presença de } \\
\text { mulheres em cargos de alta administração e o valor e desempenho } \\
\text { das empresas no Brasil. No entanto, em alguns modelos } \\
\text { econométricos, empresas que possuem pelo menos duas mulheres } \\
\text { no conselho tendem a apresentar maior valor e melhor desempenho. }\end{array}$ \\
\hline $\begin{array}{l}\text { Segura; } \\
\text { Formigoni, } \\
\text { Abreu e Costa } \\
(2016) \\
\end{array}$ & $\begin{array}{l}\text { Identificar se a presença de mi } \\
\text { conselho de administração poss } \\
\text { com o gerenciamento de resulta }\end{array}$ & $\begin{array}{l}\text { Há pequena participação de mulheres e uma relação positiva e } \\
\text { significativa entre gerenciamento de resultados e a presença de } \\
\text { mulheres no conselho de administração. }\end{array}$ \\
\hline $\begin{array}{l}\text { Silva Júnior e } \\
\text { Martins (2017) }\end{array}$ & $\begin{array}{l}\text { Analisar a influência da participação } \\
\text { feminina nos conselhos de administração } \\
\text { sobre a performance das organizações. }\end{array}$ & $\begin{array}{l}\text { Iheres em seu } \\
\text { feminina nos } \\
\text { características } \\
\text { empresas com } \\
\end{array}$ \\
\hline $\begin{array}{l}\text { Dal Magro; } \\
\text { Carpes; } \\
\text { Vergini, e Silva } \\
\quad(2018)\end{array}$ & $\begin{array}{l}\text { Identificar a incidência de glass ceiling } \\
\text { nos cargos de board e seu impacto no } \\
\text { desempenho organizacional das } \\
\text { companhias brasileiras de capital aberto. }\end{array}$ & $\begin{array}{l}\text { Os investidores não criam barreiras à valorização das empresas que } \\
\text { promovem igualdade de gênero nos cargos de board. Quando o glass } \\
\text { ceiling não incide nos cargos de diretoria e no conselho de } \\
\text { administração, as empresas alcançam melhor desempenho } \\
\text { financeiro-econômico se comparadas às que não tem mulheres em } \\
\text { tais cargos. }\end{array}$ \\
\hline $\begin{array}{l}\text { Schmiliver; } \\
\text { Teixeira; } \\
\text { Brandão; } \\
\text { Andrade e Jucá } \\
\text { (2019) }\end{array}$ & $\begin{array}{l}\text { Verificar se a presença de mulheres no } \\
\text { conselho de administração e na diretoria } \\
\text { aumenta o valor da empresa e melhora a } \\
\text { performance financeira. }\end{array}$ & $\begin{array}{l}\text { A presença feminina aumenta o valor da empresa, ratificando as } \\
\text { teorias institucional e de dependência de recursos e, por sua vez, a } \\
\text { presença de mulheres no conselho de administração e diretoria } \\
\text { melhora a performance financeira e, corrobora as teorias de agência } \\
\text { e do capital humano. }\end{array}$ \\
\hline
\end{tabular}
Fonte: Autores (2020).

Sun, Kent, Qi e Wang (2017) investigaram se cognições, valores e percepções da administração estão associados à fraude em 18.863 empresas chinesas/ano, entre 2000 a 2014. As características do diretor financeiro (CFO) são usadas como proxies para as cognições, valores e percepções da administração, descobrindo que relatórios financeiros fraudulentos são comuns quando os CFOs são jovens, do sexo masculino e têm menor nível de escolaridade.

Ho, Li, Tam e Zhang (2015) examinaram a relação entre o gênero do CEO e o conservadorismo contábil e encontraram uma associação positiva entre os dois. Consistente com a sabedoria convencional, essa associação parece ser mais forte em empresas com riscos elevados, em vez de baixos, de litígios e aquisições.

Wahid (2019) verificou o impacto da presença feminina do conselho na má conduta financeira e verificaram que empresas com conselhos diversificados cometem menos erros de relatórios financeiros e se envolvem em menos fraudes.

Zalata, Tauringana e Tingbani (2018) mostraram que a proporção de mulheres especialistas em finanças no CA está associada a menor gerenciamento de resultados, enquanto a proporção de homens especialistas em finanças não o afeta; isso sugere que a presença de um especialista financeiro no CA pode ser influenciada pelo sexo do especialista.

Os resultados de Ye, Zhang e Rezaee (2010) apontaram que proxies de qualidade de lucros, incluindo persistência de lucros, precisão dos lucros atuais na previsão de fluxos de caixa futuros, a associação entre lucros e retornos de ações e a magnitude absoluta dos acréscimos discricionários não apresentam diferenças significativas para empresas com executivos do sexo feminino e masculino na China, devido a propagação da ideologia igualitária socialista desde a fundação da China comunista em 1949, enquanto nos países desenvolvidos, como nos EUA e no Reino Unido, as mulheres possuem expectativas de papéis sociais diferentes.

Srinidhi, Gul e Tsui (2011) investigaram associação das mulheres pertencentes aos cargos da diretoria das empresas com a qualidade dos lucros e apontaram que as empresas que possuem maior participação das mulheres nos conselhos apresentam melhor qualidade dos lucros.

Pelos achados das pesquisas se acredita que a presença feminina melhora a qualidade dos lucros e, além disso auxilia no enriquecimento das informações e dos relatórios financeiros das empresas, o que diminui os custos informacionais dos investidores e aumenta a informatividade do preço das ações nos mercados.

\subsection{Construção das Hipóteses}

Estudos que abordam a influência da presença feminina nos cargos de lideranças na qualidade das informações financeiras divulgadas pelas companhias de capital aberto são incipientes e possuem resultados inconclusivos (Ismail et al., 2020). As pesquisas anteriores apontam que a presença feminina está significativamente associada à diminuição da discricionaridade dos accruals e a melhoria da qualidade das informações financeiras divulgadas pelas companhias de capital aberto (Barua et al., 2010; Dhouha et al., 
2020; Gonçalves et al., 2019; Gul et al., 2011; Panzer \& Müller, 2015; Srinidhi et al., 2011). Por conseguinte, a melhoria da qualidade das informações e relatórios financeiros beneficia de maneira significativa empresas, acionistas e clientes (Grosvold et al., 2007).

Gul, Hutchinson e Lai (2013) fornecem duas razões para a inclusão de mulheres no conselho; justiça moral e a possibilidade de aumento do valor para os acionistas. A Teoria Organizacional normalmente indica que as mulheres no conselho se associam a melhores resultados organizacionais, pois sua inclusão fortalece as decisões do conselho e facilita àquelas consideradas desagradáveis por todos os membros do sexo masculino.

A melhoria da qualidade da informação contábil e financeira das companhias está relacionada ao fato que a presença feminina na diretoria e no conselho de administração amplia a qualidade das discussões empresariais, o que permite a melhor supervisão das divulgação das informações e dos relatórios financeiros (Gul et al., 2011). Além disso, auxilia os gestores e investidores a tomarem decisões mais assertivas, pois parecem refletir as preferências pessoais de risco dos gerentes. Logo, pressupõem que as práticas contábeis e, portanto os relatórios financeiros de mulheres sejam mais conservadores (Liu et al., 2016; Zalata et al., 2019). Ainda, Peni e Vähämaa (2010) evidenciaram que CFOs do gênero feminino apresentam estratégias mais conservadoras de gerenciamento de resultados.

Panzer e Müller (2015) identificaram que empresas alemãs que possuem conselhos diversificados apresentam menos accruals discricionários e grau de alavancagem financeira maior, quando o supervisor é mulher. Assim, o número e a posição de mulheres nos conselhos têm influência na qualidade dos relatórios financeiros das empresas. Bouaziz et al. (2020) verificaram a existência de relação positiva e significativa entre a dualidade e a nacionalidade do CEO com a qualidade da informação das demonstrações financeiras das empresas francesas listadas no índice de CAC All-Tradable (Bolsa de Valores Francesa).

No que tange a elaboração dos relatórios, Francis et al. (2015) afirmam que a elaboração dos relatórios financeiros de uma companhia é uma função importante dos CFOs. Barua et al. (2010) asseveram que as empresas com CFO do gênero feminino possuem menos accruals discricionários. Além disso, os relatórios financeiros possuem menos erros de estimação. Essa característica é explicada por meio da visão da teoria da aversão ao risco, que pressupõe que as mulheres são menos propensas a correr riscos. Assim, detêm critérios de julgamentos contábeis mais conservadores (Zalata et al., 2019). Srinidhi et al. (2011) também destacam influência significativa na melhoria dos relatórios financeiros que são elaborados por mulheres.

Em relação aos julgamentos contábeis mais conservadores realizados por mulheres que ocupam cargos de CFOs, Francis et al. (2015) corroboram ao investigar a relação entre a influência do gênero e o conservadorismo dos relatórios financeiros. Por meio da análise do período pré e pós-transição de mulheres no cargo de CFO, em empresas americanas, os autores concluíram que CFO do gênero feminino são mais conservadoras na elaboração dos relatórios financeiros. Assim, a aversão ao risco de mulheres como CFO, está menos associada a remuneração baseada em ações, diminuição do risco da empresa, aumento da tangibilidade e diminuição do nível do pagamento de dividendos.

Shawver, Bancroft e Sennetti (2005) indicaram que contadoras são menos propensas a se envolverem em ações de gerenciamento de resultados do que os contadores. Os autores ainda comentam que geralmente, as contadoras são "mais sensíveis à fraude". No entanto, pesquisas apontam que essa vantagem é mitigada por diferentes socializações, restrições ambientais ou organizacionais.

Gonçalves, Gaio e Santos (2019) analisaram como a presença de mulheres no conselho de administração e nos cargos de CEO e CFO afetam a gestão de resultados das empresas cotadas europeias. Os resultados do estudo sugerem que apenas a presença feminina no cargo de CFO tem impacto na magnitude e na gestão dos resultados. Para os autores, as empresas com CFO de gênero feminino apresentam menos discricionariedade dos accruals ao comparar com as empresas que possuem CFO homens. Além disso, detectaram que empresas com mulheres no cargo de gestão, apresentam gerenciamento de resultados no sentido descendente, ou seja, usam os accruals discricionários para gerir os resultados para baixo. Kim et al. (2017) também encontraram indícios de que mulheres em cargos executivos desempenham papel relevante na formulação de relatórios éticos, mesmo que a cultura predominante seja masculina, onde se encontra um papel moderador dessas relações predominantemente masculinas.

Investigações mais recentes consideram a relação da rotatividade exógena do CEO para investigar sua relação com a qualidade das informações financeiras e consequentemente com a dos relatórios divulgados pelas companhias de capital aberto. Nesta perspectiva, o estudo de Wells (2020) evidencia como as características do indivíduo afeta a qualidade dos accruals. $O$ autor efetua a separação das características da empresa das características dos gerentes para análise da influência na qualidade dos accruals e os resultados indicam que o impacto dos gerentes nas escolhas das empresas vai além das decisões sobre investimentos que influenciam o ambiente geral das informações contábeis.

Em resumo, a literatura evidencia que a presença feminina nos cargos de CEO e CFO influencia a qualidade dos relatórios financeiros das empresas, uma vez que as mulheres são mais conservadoras nos julgamentos contábeis e mais avessas ao risco. Porém, essas constatações correspondem a achados de pesquisas aplicadas no contexto de países desenvolvidos, ao passo que há poucas evidências empíricas desta temática em países em desenvolvimento e em economias emergentes. No caso do presente estudo, 
será investigada a relação da presença feminina em cargos de CEO e CFO em empresas listadas na bolsa de valores brasileira.

Diante do contexto, são formuladas as hipóteses do presente estudo:

H1a: Empresas que possuem CEO do gênero feminino, possuem menos discricionariedade dos accruals e maior qualidade dos lucros, em relação as empresas que possuem CEO do gênero masculino.

H1b: Empresas que possuem CFO do gênero feminino, possuem menos discricionariedade dos accruals e maior qualidade dos lucros, em relação as empresas que possuem CFO do gênero masculino

\section{Procedimentos metodológicos}

\subsection{Amostra e coleta de dados}

A população do estudo é formada por todas as empresas não financeiras listadas na B3 S/A, conforme classificação por setor do North American Industry Classification System (NAICS) Nível 2, sendo excluída da amostra empresas pertencentes aos setores de administração de empresas e empreendimentos, instituições de crédito e atividade relacionadas, investimento em títulos, commodities e atividades relacionadas, seguradoras e corretora de seguros, serviço de processamento de dados, hospedagem e outros serviços relacionados e empresas de locações e leasing, obtendo-se uma amostra inicial de 283 empresas. A exclusão das empresas que não apresentaram todas as informações referentes as variáveis para o cálculo dos modelos de accruals e para o modelo econométrico foi realizada e a amostra final da pesquisa é de 179 empresas.

Em relação ao período analisado, os dados são anuais e compreendem o período de 2013 a 2018, porém, além da coleta dos dados anuais foi necessário efetuar a coleta de dados trimestrais para todas as empresas para o cálculo dos accruals discricionários correspondentes ao modelo de Dechow e Dichev (2002) adaptado por Francis et al. (2005) que compreende o período do $4^{\circ}$ trimestre de 2012 ao $1^{\circ}$ trimestre de 2019.

As variáveis do estudo foram coletadas nas Demonstrações Contábeis e nos Formulários de Referência das bases (i) economatica® e (ii) tatianaalbanez além do website da B3 S/A (Tabela 2).

\subsection{Modelo empírico}

Para responder as hipóteses do presente estudo $\mathrm{H} 1 \mathrm{a}$ e $\mathrm{H} 1 \mathrm{~b}$ de que a presença de mulheres nos cargos de CEO e CFO diminui a discricionariedade dos accruals e aumenta a qualidade dos lucros, se elaborou o modelo empírico apresentado na equação 1:

$$
\begin{aligned}
\text { TCA_BP }_{\mathrm{j}, \mathrm{t}}=\alpha_{\mathrm{it}} & +\beta_{1} \mathrm{CEO}_{\mathrm{j}, \mathrm{t}}+\beta_{2} \mathrm{CFO}_{\mathrm{j}, \mathrm{t}}+\beta_{3} \mathrm{DESEM}_{\mathrm{j}, \mathrm{t}}+\beta_{4} \mathrm{TAM}_{\mathrm{j}, \mathrm{t}}+\beta_{5} \mathrm{ENDIV}_{\mathrm{j}, \mathrm{t}}+\beta_{6} \mathrm{MB}_{\mathrm{j}, \mathrm{t}}+\beta_{7} \mathrm{GOV}_{\mathrm{j}, \mathrm{t}}+\beta_{8} \mathrm{AUD}_{\mathrm{j}, \mathrm{t}} \\
& +\beta_{9} \mathrm{CICLOOP}_{\mathrm{j}, \mathrm{t}}+\beta_{10} 2014_{\mathrm{j}, \mathrm{t}}+\beta_{11} 2015_{\mathrm{j}, \mathrm{t}}+\beta_{12} 2016_{\mathrm{j}, \mathrm{t}}+\beta_{13} 2017_{\mathrm{j}, \mathrm{t}}+\beta_{14} 2018_{\mathrm{j}, \mathrm{t}} \\
& +\varepsilon_{\mathrm{it}}
\end{aligned}
$$

Para a análise de sensibilidade do modelo se substituiu a variável dependente de accruals discricionários calculados pelo caixa operacional das empresas, conforme modelo econométrico apresentado na equação 2:

$$
\begin{aligned}
\text { TCA_CASH }_{\mathrm{j}, \mathrm{t}}= & \alpha_{\mathrm{it}} \\
& +\beta_{1} \mathrm{CEO}_{\mathrm{j}, \mathrm{t}}+\beta_{2} \mathrm{CFO}_{\mathrm{j}, \mathrm{t}}+\beta_{3} \mathrm{DESEM}_{\mathrm{j}, \mathrm{t}}+\beta_{4} \mathrm{TAM}_{\mathrm{j}, \mathrm{t}}+\beta_{5} \mathrm{ENDIV}_{\mathrm{j}, \mathrm{t}}+\beta_{6} \mathrm{MB}_{\mathrm{j}, \mathrm{t}}+\beta_{7} \mathrm{GOV}_{\mathrm{j}, \mathrm{t}}+\beta_{8} \mathrm{AUD}_{\mathrm{j}, \mathrm{t}} \\
& +\beta_{9} \mathrm{CICLOOP}_{\mathrm{j}, \mathrm{t}}+\beta_{10} 2014_{\mathrm{j}, \mathrm{t}}+\beta_{11} 2015_{\mathrm{j}, \mathrm{t}}+\beta_{12} 2016_{\mathrm{j}, \mathrm{t}}+\beta_{13} 2017_{\mathrm{j}, \mathrm{t}}+\beta_{14} 2018_{\mathrm{j}, \mathrm{t}} \\
& +\varepsilon_{\mathrm{it}}
\end{aligned}
$$

O modelo multivariado, por meio do modelo de regressão quantílica, para verificar a influência da presença feminina na qualidade dos accruals das empresas não financeiras listadas na B3 S/A foi utilizado. A regressão quantílica de acordo com Fávero e Belfiore (2017) permite a estimação de diferentes percentis para efetuar a análise da variável dependente (Tabela 2). 
Tabela 2:

Variáveis do estudo

\begin{tabular}{|c|c|c|c|}
\hline \multicolumn{4}{|c|}{ Variáveis dependentes } \\
\hline Variável & Descrição & Operacionalização & Referências \\
\hline \multirow[b]{2}{*}{ AQCASH } & Accruals Discricionários & $\begin{array}{c}\frac{\mathrm{TCA}_{-} \mathrm{BP}_{\mathrm{j}, \mathrm{t}}}{\mathrm{AT}_{\mathrm{j}, \mathrm{t}}}=\varphi_{0, \mathrm{j}}+\varphi_{1, \mathrm{j}} \frac{\mathrm{CFO}_{\mathrm{j}, \mathrm{t}-1}}{\mathrm{AT}_{\mathrm{j}, \mathrm{t}}}+\varphi_{2, \mathrm{j}} \frac{\mathrm{CFO}_{\mathrm{j}, \mathrm{t}}}{\mathrm{AT}_{\mathrm{j}, \mathrm{t}}}+\varphi_{3, \mathrm{j}} \frac{\mathrm{CFO}_{\mathrm{j}, \mathrm{t}+1}}{\mathrm{AT}_{\mathrm{j}, \mathrm{t}}}+\varphi_{4, \mathrm{j}} \frac{\Delta \mathrm{REC}_{\mathrm{j}, \mathrm{t}}}{\mathrm{AT}_{\mathrm{j}, \mathrm{t}}} \\
+\varphi_{5, \mathrm{j}} \frac{\mathrm{IMOB}_{\mathrm{j}, \mathrm{t}}}{\mathrm{AT}_{\mathrm{j}, \mathrm{t}}}+\varepsilon_{\mathrm{j}, \mathrm{t}}\end{array}$ & Francis et al. (2005) \\
\hline & Accruals Discricionários & $\begin{aligned} \frac{\mathrm{TCA}_{-} \mathrm{CASH}_{\mathrm{j}, \mathrm{t}}}{\mathrm{AT}_{\mathrm{j}, \mathrm{t}}}=\varphi_{0, \mathrm{j}}+ & \varphi_{1, \mathrm{j}} \frac{\mathrm{CFO}_{\mathrm{j}, \mathrm{t}-1}}{\mathrm{AT}_{\mathrm{j}, \mathrm{t}}}+\varphi_{2, \mathrm{j}} \frac{\mathrm{CFO}_{\mathrm{j}, \mathrm{t}}}{\mathrm{AT}_{\mathrm{j}, \mathrm{t}}}+\varphi_{3, \mathrm{j}} \frac{\mathrm{CFO}_{\mathrm{j}, \mathrm{t}+1}}{\mathrm{AT}_{\mathrm{j}, \mathrm{t}}}+\varphi_{4, \mathrm{j}} \frac{\Delta \mathrm{REC}_{\mathrm{j}, \mathrm{t}}}{\mathrm{AT}_{\mathrm{j}, \mathrm{t}}} \\
& +\varphi_{5, \mathrm{j}} \frac{\mathrm{IMOB}_{\mathrm{j}, \mathrm{t}}}{\mathrm{AT}_{\mathrm{j}, \mathrm{t}}}+\varepsilon_{\mathrm{j}, \mathrm{t}}\end{aligned}$ & Francis et al. (2005) \\
\hline \multicolumn{4}{|c|}{ Variáveis para o cálculo dos Accruals Discricionários } \\
\hline Variáveis & Descrição & Operacionalização & Referências \\
\hline TCA_BP & Accruals Totais & $\mathrm{TCA}_{-} \mathrm{BP}_{\mathrm{j}, \mathrm{t}}=\Delta A C_{j, t}-\Delta P C_{j, t}-\Delta C A S H_{j, t}+\Delta S T D_{j, t}-D E P_{j, t}$ & $\begin{array}{l}\text { Dechow e Dichev (2002) } \\
\text { Francis et al. (2005) }\end{array}$ \\
\hline $\begin{array}{l}\text { TCA_CASH } \\
\text { CFO }\end{array}$ & $\begin{array}{c}\text { Accruals Totais } \\
\text { Caixa e Equivalentes de Caixa }\end{array}$ & $\mathrm{TCA}_{-} \mathrm{CASH}_{\mathrm{j}, \mathrm{t}}=L L_{j, t}-C A S H_{-} O P_{j, t}$ & Dechow e Dichev (2002) \\
\hline$\triangle \mathrm{REC}$ & Variação da Receita & $\Delta R E C_{\mathrm{j}, \mathrm{t}}=R E C_{j, t}-R E C_{j, t-1}$ & Francis et al. (2005) \\
\hline IMOB & Imobilizado & Total do imobilizado da empresa & Francis et al. (2005) \\
\hline$\Delta \mathrm{AC}$ & Variação do Ativo circulante & $\Delta A C_{\mathrm{j}, \mathrm{t}}=A C_{j, t}-A C_{j, t-1}$ & Francis et al. (2005) \\
\hline$\triangle \mathrm{PC}$ & Variação do Passivo Circulante & $\Delta P C_{\mathrm{j}, \mathrm{t}}=P C_{j, t}-P C_{j, t-1}$ & Francis et al. (2005) \\
\hline$\triangle \mathrm{CASH}$ & Variação do caixa e Equivalentes & $\Delta C A S H_{i, t}=C A S H_{j, t}-C A S H_{j, t-1}$ & Francis et al. (2005) \\
\hline$\triangle S T D$ & $\begin{array}{l}\text { Variação dos Empréstimos e } \\
\text { Financiamentos do Curto Prazo }\end{array}$ & $\Delta S T D_{\mathrm{j}, \mathrm{t}}=S T D_{j, t}-S T D_{j, t-1}$ & Francis et al. (2005) \\
\hline DEP & Depreciação & Despesa de depreciação do período & Francis et al. (2005) \\
\hline & Lucro Líquido & Lucro Líquido do período & Dechow e Dichew (2002) \\
\hline CASH OP & Caixa operacional & Total do caixa operacional da empresa no período & Dechow e Dichew (2002) \\
\hline \multicolumn{4}{|c|}{ Variáveis independentes } \\
\hline Variáveis & Descrição & Operacionalizacão & Referências \\
\hline CEO & $\begin{array}{l}\text { Diretor Financeiro/Diretor de Relações } \\
\text { com Investidor }\end{array}$ & $\begin{array}{l}\text { Variável Dummy: } \\
\text { 0- Gênero masculino } \\
1 \text { - Gênero feminino }\end{array}$ & $\begin{array}{c}\text { Gonçalves et al. (2019) } \\
\text { Liu et al. (2016) } \\
\text { Panzer e Müller (2015) } \\
\text { Habib e Hossain (2013) } \\
\text { Gul et al. (2011) } \\
\text { Barua et al. (2010) } \\
\text { Dhouha et al. (2020) } \\
\text { Liu et al. (2016) } \\
\text { Terjesen, Couto e Francisco } \\
\text { (2016) } \\
\text { Srinidhi et al. (2011) } \\
\text { Adams e Ferreira (2009) }\end{array}$ \\
\hline
\end{tabular}




\begin{tabular}{|c|c|c|c|}
\hline \multicolumn{4}{|c|}{ Variáveis de Controle } \\
\hline Variáveis & Descrição & Operacionalização & Referências \\
\hline GOV & $\begin{array}{l}\text { Nível Governança } \\
\text { Brasil Bolsa Balcão }\end{array}$ & 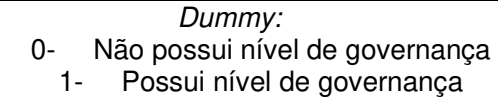 & $\begin{array}{c}\text { Gul et al. (2011) } \\
\text { Adams e Ferreira (2009) }\end{array}$ \\
\hline TAM & Logaritmo natural do ativo total & 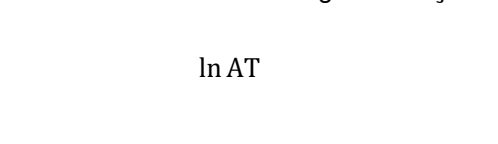 & $\begin{array}{c}\text { Liu et al. (2016) } \\
\text { Gul et al. (2011) } \\
\text { Barua et al. (2010) } \\
\text { Dechow e Dichev (2002) }\end{array}$ \\
\hline MTB & Market-to-Book & $\mathrm{MB}=\frac{\text { Vlr. Mercado }}{\mathrm{PL}}$ & $\begin{array}{c}\text { Gonçalves et al. (2019) } \\
\text { Liu et al. (2016) } \\
\text { Gul et al. (2011) } \\
\text { Barua et al. (2010) } \\
\text { Gonçalves et al. (2019) }\end{array}$ \\
\hline ROA & Rentabilidade do Ativo & $R O A=\frac{\text { Lucro Líquido }+P A M}{\text { Ativo Total }} * 100$ & $\begin{array}{c}\text { Liu et al. (2016) } \\
\text { Gul et al. (2011) } \\
\text { Srinidhi et al. (2011) } \\
\text { Adams e Ferreira (2009) }\end{array}$ \\
\hline $\mathrm{CCO}$ & Ciclo Operacional & CICLOOP $=$ PME + PMR - PMF & $\begin{array}{l}\text { Srinidhi et al.(2011) } \\
\text { Barua et al. (2010) }\end{array}$ \\
\hline LG & Índice de Liquidez Geral & Liq. Geral $=\frac{A T+R P L}{P C+P N C}$ & Gonçalves et al. (2019) \\
\hline BIG4 & Empresa de Auditoria & $\begin{array}{l}\text { Variável Dummy: } \\
\text { 0- Não Big Four } \\
1-\quad \text { Big Four }\end{array}$ & $\begin{array}{l}\text { Srinidhi et al. (2011) } \\
\text { Barua et al. (2010) }\end{array}$ \\
\hline
\end{tabular}




\section{Apresentação e análise dos resultados}

\subsection{Análise descritiva de da correlação das variáveis}

Os resultados do estudo em relação à quantidade de mulheres como CEOs e CFO apontam 25 mulheres (2,68\%) CEOs e 72 (7,73\%) em cargos de CFOs totalizando 97, o que aponta baixa presença feminina. Os dados confirmam os dizeres de Hryniewicz e Vianna (2018) que afirmam que as mulheres apresentam baixa representatividade nos cargos de CEO, CFO e COO. Ainda, os resultados demonstram que $76,72 \%$ das empresas analisadas são listadas em alguns dos níveis de governança corporativa da B3 S/A e $80,90 \%$ são auditadas por empresas BIG4 de auditoria.

A análise descritiva dos dados quantitativos que compõem o modelo econométrico é apresentada na Tabela 3. Em relação a análise das variáveis dependentes, se nota que os accruals discricionários (AQBP) apresentam média de $-0,03$. Os resultados apresentados vão de encontro aos achados de Gonçalves et al. (2019), Na e Hong (2017), Wells (2020). As medidas de accruals discricionários (AQBP; AQC) apresentam a mesma média para ambas as análises, o que salienta a robustez e a validade da medida de accruals utilizada no modelo econométrico principal.

No que tange ao tamanho das empresas (TAM), a média de 15,23 no período analisado. Além disso, ao verificar a média dos índices de Market-to-Book que evidencia a relação entre o valor de mercado e o patrimônio líquido das empresas, os resultados apontam um índice médio de 1,95, ou seja, os investidores estão pagando em média $R \$ 1,95$ por cada $R \$ 1,00$ registrado no patrimônio líquido da empresa. No que se refere a rentabilidade do ativo (ROA), as empresas analisadas apresentam em média um índice ROA de 5,95.

Tabela 3:

Estatística descritiva das variáveis quantitativas

\begin{tabular}{cccccc}
\hline Variáveis & OBS & Média & Desvio Padrão & Mínimo & Máximo \\
\hline AQBP & 932 & $-0,03$ & 0,02 & $-0,13$ & 0,00 \\
AQCASH & 932 & $-0,03$ & 0,02 & $-0,12$ & 2,00 \\
TAM & 932 & 15,23 & 1,70 & 9,64 & 0,62 \\
MTB & 932 & 1,95 & 2,38 & 02 & 26,83 \\
ROA & 932 & 5,95 & 5,07 & 37,01 & 3,80 \\
CCO & 932 & 284,23 & 2906,48 & 0,06 & 19,74 \\
LG & 932 & 1,30 & 1,46 & 0,56 \\
\hline
\end{tabular}

Legenda: AQBP - Accruals discricionários Balanço Patrimonial; AQCASH - Accruals discricionários Caixa Operacional; TAM - Ln do ativo total; MTB- Market-to-book; ROA - Rentabilidade do Ativo; CCO - Ciclo Operacional; LG - Liquidez Geral.

Fonte: Dados da pesquisa (2020).

As empresas necessitam em média de 284 dias para realizar o ciclo operacional e apresentam um índice médio de liquidez geral (LG) de 1,30, ou seja, os resultados apontam que as empresas possuem recursos suficientes para honrar seus compromissos de curto, médio e longo prazo.

Observa-se na Tabela 4, a matriz de correlação de Spearmann que segundo Fávero e Belfiore (2017) é o modelo de análise de correlação mais indicado quando se têm no mesmo modelo a utilização de variáveis quantitativas e qualitativas.

Tabela 4:

Matriz de correlação Spearmann

\begin{tabular}{|c|c|c|c|c|c|c|c|c|c|c|c|}
\hline (2) & AQBP & AQC & GOV & CEO & CFO & TAM & MTB & ROA & CCO & LG & BIG4 \\
\hline AQBP & 1,00 & & & & & & & & & & \\
\hline AQCASH & $0,18^{*}$ & 1,00 & & & & & & & & & \\
\hline GOV & $-0,07^{*}$ & $-0,07^{*}$ & 1,00 & & & & & & & & \\
\hline CEO & 0,02 & 0,01 & 0,01 & 1,00 & & & & & & & \\
\hline CFO & 0,01 & 0,05 & 0,01 & $0,16^{*}$ & 1,00 & & & & & & \\
\hline TAM & $0,10^{*}$ & $0,08^{*}$ & $0,20^{*}$ & 0,02 & $-0,05$ & 1,00 & & & & & \\
\hline MTB & $-0,23^{*}$ & 0,00 & 0,04 & $-0,02$ & 0,01 & $0,12^{*}$ & 1,00 & & & & \\
\hline ROA & $-0,17^{*}$ & $-0,19^{*}$ & 0,00 & $-0,01$ & 0,03 & $-0,20^{*}$ & $0,28^{*}$ & 1,00 & & & \\
\hline $\mathrm{CCO}$ & 0,01 & 0,04 & $0,07^{*}$ & 0,03 & $-0,04$ & $-0,20^{*}$ & $-0,27^{*}$ & $-0,02$ & 1,00 & & \\
\hline LLG & $-0,08^{*}$ & $-0,02$ & $-0,01$ & $-0,01$ & 0,03 & $-0,41$ & $-0,15^{*}$ & $0,22^{*}$ & $0,43^{*}$ & 1,00 & \\
\hline BIG4 & $-0,01$ & 0,00 & $0,29^{*}$ & $-0,04$ & 0,01 & $0,35^{*}$ & $0,20^{*}$ & $-0,07^{*}$ & $-0,13^{*}$ & $-0,14^{*}$ & 1,00 \\
\hline
\end{tabular}

Legenda: AQBP - Accruals discricionários Balanço Patrimonial; AQCASCH - Accruals discricionários Caixa Operacional; GOV - Nível de Governança Corporativa; TAM - Ln do ativo total; MTB- Market-to-book; ROA - Rentabilidade do Ativo; CCO - Ciclo Operacional; LG - Liquidez Geral.

*nível de significância a $10 \%$

**nível de significância a $5 \%$

***nível de significância a $1 \%$

Fonte: Dados da pesquisa (2020).

As variáveis independentes não apresentam forte correlação entre si, portanto diminui a incidência de problemas de multicolinearidade, o que foi apresentado na Tabela 4. 


\subsection{Análise e discussões dos resultados}

A relação da presença de mulheres como CEO e a diminuição da discricionariedade dos accruals, apresentada na Tabela 5 não apontou evidências significativas, assim, não é possível afirmar que a presença feminina como CEO da empresa diminui a discricionariedade dos accruals. Os achados da pesquisa corroboram com os achados de Gonçalves et al. (2019), Peni e Vähämaa (2010), que também não evidenciaram relação significativa da presença de mulheres como CEO e a diminuição da discricionariedade dos accruals. Ainda, contradiz os achados de Dhouha et al.(2020) com influência positiva e significativa da presença de mulheres como CEO com a melhoria da qualidade das demonstrações contábeis. Porém, as empresas que compõem o quartil 0,10 , apresentaram uma relação negativa e significativa referente a presença feminina e a diminuição da discricionariedade dos accruals.

As empresas que compõem os quartis 0,75 e 0,90 apresentam relação positiva e significativa da presença feminina como CFOs na diminuição da discricionariedade dos accruals (Tabela 5). Esses resultados condizem com Barua et al. (2010), Gonçalves et al. (2019) que também encontraram relação positiva e significativa da presença feminina como CFOs na diminuição da discricionariedade dos accruals e por consequência na melhoria dos relatórios financeiros e contábeis. Ainda, corrobora com os achados de Wells (2020) que identificou esta associação ao examinar a presença feminina e as características dos indivíduos que ocupam cargos de CFOs com a diminuição da discricionariedade dos accruals.

Kim et al. (2017) também identificam que a presença feminina no cargo de CFO possui desempenho relevante na formulação de relatórios mais éticos e com maior qualidade das informações financeiras referentes às empresas coreanas, onde os aspectos culturais são de predominância masculina. Ainda, Francis et al. (2015) e Srinidhi et al. (2011) alertam que empresas com CFOs do gênero feminino possuem relatórios mais conservadores do que as empresas que tem presença masculina.

Em relação as hipóteses pressupostas no estudo, os resultados rejeitam a hipótese $\mathrm{H} 1 \mathrm{a}$, ou seja, não foi encontrada influência significativa da presença feminina no cargo de CEO com a diminuição da discricionariedade dos accruals nas empresas analisadas. Em contrapartida, os e resultados encontrados nos quartis $(0,10 ; 0,75$ e 0,90$)$ não rejeitam a hipótese $\mathrm{H} 1 \mathrm{~b}$, portanto, foi encontrado evidências significativas que a presença feminina no cargo de CFO auxilia na diminuição da discricionariedade dos accruals das empresas que compõem os quartis $(0,10 ; 0,75$ e 0,90$)$ analisados no estudo.

Os resultados obtidos para as variáveis de controle apresentou relação significativa entre as variáveis de tamanho (TAM); Market-to-Book (MTB) com a discricionariedade dos accruals em todos os quartis analisados, já o desempenho (ROA) também apresenta relação significativa exceto no quartil 0,90. o que corrobora com Gonçalves et al. (2019) em relação a significância da variável de MTB e ROA. 
Tabela 5:

Análise multivariada dos dados

Qualidade dos accruals pelo método do Balanço Patrimonial

VAR

\begin{tabular}{lcc}
\cline { 2 - 3 } & \multicolumn{2}{c}{$\mathbf{0 , 1 0}$} \\
\cline { 2 - 3 } & Coef. \\
\hline CEO & 0,0033 & $-0,0091$ \\
CFO & $-0,0076$ & \\
GOV & 0,0022 & \\
TAM & $-0,0033$ & -3 \\
MTB & $-0,0006$ & -1, \\
ROA & $3,73 e^{-07}$ \\
CCO & $-0,0004$ \\
LG & $-0,0013$ \\
BIG4 & $-0,0746$ & $-0,0$ \\
\hline Cons & &
\end{tabular}

\begin{tabular}{ccc} 
& \multicolumn{2}{c}{$\mathbf{0 , 2 5}$} \\
Est T & Coef. & Est T \\
0,41 & $-0,0042$ & $-1,13$ \\
$-2,58^{\star \star}$ & $-0,0067$ & $-1,57$ \\
$-0,98$ & $-0,0077$ & $-1,38$
\end{tabular}

$\begin{array}{lll}-0,00077 & -1,38 & -0,0018 \\ 0,0020 & 2,38 & -0,0036\end{array}$

$\begin{array}{ccc}\text { Coef. } & \text { Est T } & \text { Coef. } \\ 0,0063 & 0,58 & -0,0014 \\ -0,0018 & -0,35 & 0,0058 \\ -0,0036 & -0,81 & -0,0011\end{array}$

$-0,0036 \quad-0,81$

$2,70^{* *} \quad 0,0020 \quad 2,38^{* *} \quad 0,0015$

$-0,0020$

$2,55^{* *}$

$-0,001$

0,0009

$\begin{array}{ll}-3,81^{* * *} & -0,0020 \\ -2,17^{\star *} & -0,0004 \\ 0,00 & 1,98 e^{-07}\end{array}$

$\begin{array}{ccc}-0,0007 & -2,17^{* *} & -0,0004 \\ 7,46 \mathrm{e}^{-08} & 0,00 & 1,98 \mathrm{e}^{-07} \\ 0,0002 & 0,07 & -0,0009\end{array}$

$0,01 \quad 7,46 \mathrm{e}^{-08}$

Cons

0,0073

$\begin{array}{rr}-0,12 & -0,0014 \\ -4,04^{\star \star \star} & -0,0548\end{array}$

$\begin{array}{ll}0,07 & -0,0009 \\ -0,27 & -0,0019\end{array}$

$-2,47^{\star *}$

$\begin{array}{lll}-0,0014 & -0,27 & -0,0019 \\ -0,0548 & -3,72 & -0,0390\end{array}$

$-1,97^{* *}$

0,0688

$0,0390 \quad 0,0533$

$-0,43$

$-0,0014$
$-0,00042$
$-3,69 e^{-07}$

$-0,0009$

$-0,0011$

0,75

$\begin{array}{ll} & \\ \text { Est T } & -1,07 \\ 45^{\star \star \star} & -0,0 \\ -0,40 & -0,0\end{array}$

0,90

Coef.

$-0,0004$
0,0063

$\begin{array}{ll}0,0063 & -0,31 \\ -0,0025 & 2,15^{\star \star}\end{array}$

0,0430

$\begin{array}{ccc}3,45^{\star * \star} & 0,0063 & 2,15^{\star *} \\ -0,40 & -0,0025 & -1,07 \\ 2,81^{\star *} & 0,0010 & 3,00^{\star *}\end{array}$

$\begin{array}{ccc}2,81^{* *} & 0,0010 & 3,00^{* *} \\ -2,04^{* *} & -0,0005 & -0,81\end{array}$

$\begin{array}{lll}-2,04^{* *} & -0,0005 & -0,81 \\ -2,39^{* *} & -0,0001 & -0,72\end{array}$

$\begin{array}{lll}-0,02 & -0,11 \mathrm{e}^{-07} & -0,04 \\ -0,51 & -0,0010 & -1,23\end{array}$

$\begin{array}{lll}-0,51 & -0,0010 & -1,23 \\ -0,45 & -0,0006 & -0,36\end{array}$

$\begin{array}{rrr}-0,45 & -0,0006 & -0,36 \\ -2,70^{* *} & -0,0160 & -2,65^{* *}\end{array}$

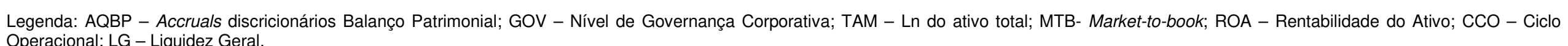

"nível de significância a $10 \%$

**nível de significância a 5\%

Fonte: Dados da pesquisa (2020) 
As variáveis níveis de governança (GOV), liquidez geral (LG), auditoria (BIG4) e ciclo operacional (CCO) não apresentam influência significativa com a diminuição da discricionariedade dos accruals. Achados que contradizem as pesquisas de Edwards et al. (2013), onde o nível de gerenciamento dos accruals é menor em empresas que apresentam níveis mais altos de governança corporativa. Além, das evidencias encontradas nas pesquisas de Barua et al. (2010) e Gul et al. (2011) que empresas serem auditadas por BIG4 não apresenta relação significativa com a diminuição da discricionariedade dos accruals.

Ainda em relação ao resultado apresentado na Tabela 5, se percebeu que o modelo apresenta $\mathrm{R}^{2}$ de 20,55 , portanto o modelo econométrico proposto explica $20,55 \%$ da variação do comportamento das variáveis e dos resultados encontrados no modelo.

\subsection{Análise de sensibilidade}

Para a análise de sensibilidade foi realizada a alteração do método do cálculo dos accruals discricionários sob a perspectiva das variáveis que compõem o Balanço Patrimonial para a abordagem de Dechow e Dichev (2002) que utilizam a perspectiva do modelo com as variáveis relacionadas ao fluxo de caixa operacional. O modelo de sensibilidade apresenta um $\mathrm{R}^{2}$ de 31,34 , ou seja, o modelo explica $31,34 \%$ da variabilidade dos resultados encontrados no modelo econométrico proposto.

Os resultados demonstram que não há influência significativa da presença feminina nos cargos de CEO com a diminuição da discricionariedade dos accruals (Tabela 6). Assim, se comprova os resultados evidenciados na seção anterior que também não encontrou relação significativa da influência da presença de mulheres como CEO com a diminuição da discricionariedade dos accruals.

Em relação aos achados que verificam a influência da presença feminina como CFOs na diminuição da discricionariedade dos accruals, as inferências estatísticas encontraram relação significativa nos quartis 0,$10 ; 0,25$ e 0,90, o que confirma os resultados encontrados na seção anterior apontado influência significativa entre a presença feminina como CFO e a diminuição da discricionariedade dos accruals nas empresas que pertencem a esses quartis.

Em relação as variáveis de controle, o modelo de sensibilidade também confirma os resultados apresentados na Tabela 5 , em relação as variáveis que possuem influência com a diminuição da discricionariedade dos accruals nas empresas analisadas. 


\section{Tabela 6:}

Análise de sensibilidade do modelo

\begin{tabular}{|c|c|c|c|c|c|c|c|c|c|c|}
\hline \multicolumn{11}{|c|}{ Qualidade dos accruals pelo método Caixa Operacional } \\
\hline \multirow{3}{*}{ Variáveis } & \multicolumn{10}{|c|}{ Quartis } \\
\hline & \multicolumn{2}{|c|}{0,10} & \multicolumn{2}{|c|}{0,25} & \multicolumn{2}{|c|}{0,50} & \multicolumn{2}{|c|}{0,75} & \multicolumn{2}{|c|}{0,90} \\
\hline & Coef. & Est T & Coef. & Est T & Coef. & Est T & Coef. & Est T & Coef. & Est T \\
\hline CEO & $-0,010$ & $-0,59$ & 0,0004 & 0,03 & $-0,0001$ & $-0,04$ & 0,0010 & 0,57 & $-0,0032$ & $-0,81$ \\
\hline CFO & 0,0118 & $2,02^{\star *}$ & 0,0074 & $2,19^{\star *}$ & 0,0040 & 1,44 & 0,0029 & $1,87^{\star}$ & 0,0007 & 0,56 \\
\hline GOV & $-0,0128$ & $-1,46$ & $-0,0100$ & $-1,16$ & $-0,0052$ & $-1,48$ & $-0,0002$ & $-0,08$ & 0,0002 & 0,10 \\
\hline TAM & 0,0004 & 0,40 & $-0,0000$ & $-0,02$ & 0,0007 & 1,60 & 0,0007 & $1,93^{*}$ & 0,0004 & $1,70^{*}$ \\
\hline MTB & $-0,0001$ & $-0,13$ & $-0,0001$ & $-0,14$ & $-0,0001$ & $-0,24$ & $-0,0002$ & $-0,36$ & $-0,0002$ & $-1,69$ \\
\hline ROA & $-0,0026$ & $-13,79^{\star * *}$ & $-0,0019$ & $-5,28^{\star \star \star}$ & $-0,0010$ & $-4,87^{* * *}$ & $-0,0005$ & $-3,01^{* *}$ & $-0,0002$ & $-3,34^{* *}$ \\
\hline CCO & $5,78 \mathrm{e}^{-07}$ & 0,01 & $3,37 \mathrm{e}^{-07}$ & 0,03 & $1,44 \mathrm{e}^{-07}$ & 0,00 & $2,87 \mathrm{e}^{-08}$ & $-0,00$ & $-1,55 \mathrm{e}^{-07}$ & $-0,02$ \\
\hline LG & 0,0018 & 0,68 & 0,0009 & 0,48 & 0,0007 & 0,52 & 0,0002 & 0,14 & $-0,0003$ & $-0,47$ \\
\hline BIG4 & 0,0013 & 1,58 & 0,0043 & 0,71 & $-0,0008$ & $-0,27$ & $-0,0013$ & $-0,54$ & $-0,0009$ & $-0,51$ \\
\hline Cons & $-0,0551$ & $-2,47^{\star \star}$ & $-0,0259$ & $-2,26^{\star \star}$ & \multirow{2}{*}{\multicolumn{2}{|c|}{$\begin{array}{r}-0,0279 \\
0,0398\end{array}$}} & $-0,0190$ & $-2,98^{\star \star}$ & $-0,0096$ & $-2,31^{\star \star}$ \\
\hline $\bar{P}_{\text {seudo }}{ }^{2}$ & \multicolumn{2}{|c|}{0,1376} & \multicolumn{2}{|c|}{0,0833} & & & \multicolumn{2}{|c|}{0,0243} & \multicolumn{2}{|c|}{0,0284} \\
\hline
\end{tabular}

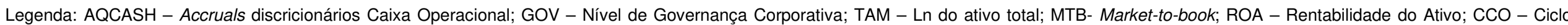
Operacional; LG - Liquidez Geral.

*nível de significância a 10\%

**nível de significância a 5\%

nivel de significância a $1 \%$

Fonte: Dados da pesquisa (2020) 


\section{Considerações finais}

Pesquisas recentes buscaram verificar a influência da presença feminina nos cargos de alto escalão, diretoria executiva e nos conselhos em relação à qualidade das informações e relatórios financeiros divulgados pelas companhias. Este estudo contribui com esta literatura ao verificar a influência do gênero do CEO e CFO na qualidade dos accruals e dos lucros das companhias abertas listadas na B3 S/A do período de 2013 a 2018.

Os resultados apontam que a presença de mulheres nos cargos de CEOs não influencia significativamente na diminuição dos accruals discricionários, assim rejeita-se a hipótese H1a do estudo. Esses resultados podem estar associados a pouca presença de mulheres nos cargos de CEO, já que apenas $2,68 \%$ da amostra apresenta mulheres ocupando cargos de CEO nas empresas analisadas. Ainda, Kim et al. (2017) afirmam que as questões culturais dos países relacionadas a presença majoritária de homens em cargos de gestão influencia o comportamento das organizações na escolha dos gestores. Já em relação a hipótese $\mathrm{H} 1 \mathrm{~b}$, os resultados não rejeitam a hipótese $\mathrm{H} 1$. Conclui-se que a influência significativa da presença feminina na diminuição dos accruals discricionários das empresas analisadas. Ao analisar as demais variáveis deste estudo, se nota que o tamanho, Market-to-book e desempenho (ROA) das empresas apresentam relação significativa com a diminuição da discricionariedade dos accruals. Ao contrário de evidências anteriores, o nível de governança, liquidez geral, ciclo operacional e a auditoria realizada por BIG4 não apresentaram associação com a diminuição da discricionariedade dos accruals.

Conclui-se que a presença feminina nos cargos de CFO auxilia para a diminuição da discricionariedade dos accruals, o que melhora a qualidade dos relatórios contábeis das empresas analisadas. Francis et al. (2015) evidenciam que o CFO desempenha papel importante na elaboração dos relatórios contábeis e financeiros divulgados pela organização.

Como limitações de pesquisa, consta a pouca representatividade feminina no cargo de CEO e CFO no cenário das empresas brasileiras listadas na B3 S/A. e ainda não foram controladas variáveis que refletem a cultura do país que podem influenciar na escolha dos gestores.

Para pesquisas futuras sugere-se investigar a relação entre a presença feminina e outras métricas de qualidade dos lucros, sobre aspectos de divulgação obrigatória e voluntária de informações relacionadas a empresa e, ainda identificar como a presença feminina influencia os critérios de julgamentos contábeis, cada vez mais presentes após a introdução das International Financial Reporting Standards (IFRS). Além disso, estudos futuros poderiam tentar explicar com maior profundidade este fenômeno de forma qualitativa.

\section{Referências}

Adams, R. B., \& Ferreira, D. (2009). Women in the boardroom and their impact on governance and performance. Journal of Financial Economics, 94(2), 291-309. https://doi.org/10.1016/i.jineco.2008.10.007

Alves, M. do C. (2010). Projeto de Lei $n^{\circ} 112$, de 2010. Define percentual mínimo de participação de mulheres nos conselhos de administração das empresas (pp. 1-8). Senado Federal. Disponível em: https://www12.senado.leg.br/ecidadania/visualizacaomateria?id=96597

Bartz, C., \& Creswell, B. J. (2006). How Suit It Isn't: A Dearth of Female Bosses. The New York Times.

Barua, A., Davidson, L. F., Rama, D. V., \& Thiruvadi, S. (2010). CFO gender and accruals quality. Accounting Horizons, 24(1), 25-39. https://doi.org/10.2308/acch.2010.24.1.25

Bouaziz, D., Salhi, B., \& Jarboui, A. (2020). CEO characteristics and earnings management: empirical evidence from France. Journal of Financial Reporting and Accounting. https://doi.org/10.1108/JFRA-01$\underline{2019-0008}$

Catalyst. (2009). Report: 2009 Catalyst Census: Fortune 500 Women Board Directors. Workplaces That Work for Women. Disponível em: https://www.catalyst.org/research/2009-catalyst-census-fortune-500women-board-directors/

Catalyst. (2019). Women on corporate boards. Workplaces That Work for Women. Disponível em: https://www.catalyst.org/research/women-on-corporate-boards/

Chan, K., Chan, L. K. C., Jegadeesh, N., \& Lakonishok, J. (2006). Earnings quality and stock returns. Journal of Business, 79(3), 1041-1082. https://doi.org/10.1086/500669

Dal Magro, C. B., Carpes, A. D., Vergini, D., \& Silva, M. Z. (2018). Glass ceiling em cargos de board e seu impacto no desempenho organizacional. Revista Contemporânea de Contabilidade, 15(34), 158-180. https://doi.org/10.5007/2175-8069.2018v15n34p158 
Dechow, P. M., \& Dichev, I. D. (2002). The Quality of Accruals and Earnings: The e Role of Accrual Estimation Errors. The Accounting Review, 77, 35-59.

Dhouha, B., Bassem, S., Anis, J., Bouaziz, D., Salhi, B., \& Jarboui, A. (2020). CEO characteristics and earnings management: empirical evidence from France. Journal of Financial Reporting and Accounting, ahead-of-p(ahead-of-print). https://doi.org/10.1108/JFRA-01-2019-0008

Durnev, A., Morck, R., \& Yeung, B. (2004). Value-Enhancing Capital Budgeting and Firm-specific Stock Return Variation. Journal of Finance, 59(1), 65-105. https://doi.org/10.1111/j.1540-6261.2004.00627.x

Edwards, M., Soares, R. O., \& Lima, G. S. de. (2013). a Relação Entre Governança Corporativa E Gerenciamento De Resultados Em Empresas Brasileiras. Revista de Contabilidade e Organizações, 7(19), 27. https://doi.org/10.11606/rco.v7i19.55509

Fávero, L. P., \& Belfiore, P. (2017). Manual de Análise de Dados. Elsevier (ed.); $1^{\circ}$.

Favoretto, A. B., Corrêa, F. P., Lopes, S. F., \& Grecco, M. C. P. (2017). O gerenciamento de resultados contábeis e o controle de provisões. Revista Eletrônica do Departamento de Ciências Contábeis \& Departamento de Atuária e Métodos Quantitativos da FEA, 4(1), 1-6. https://doi.org/10.23925/24469513.2017v4i2p113-125

Feng, M., Ge, W., Luo, S., \& Shevlin, T. (2011). Why do CFOs become involved in material accounting manipulations? Journal of Accounting and Economics, 51(1-2), 21-36.

https://doi.org/10.1016/i.jacceco.2010.09.005

Fernandes, J. C. L., Souza, M. M. de, Santana, R. dos S. de, \& Santos, V. S. (2015). Inclusão Feminina na Hierarquia Organizacional: Uma Breve Análise da Mulher na Gestão Contemporânea. Anais Do II Seminário Internacional de Integração Étnico-Racial e as Metas do Milênio, 1 (2), 162-181.

Francis, B., Hasan, I., Park, J. C., \& Wu, Q. (2015a). Gender Differences in Financial Reporting Decision Making: Evidence from Accounting Conservatism. Contemporary Accounting Research, 32(3), 1285-1318. https://doi.org/10.1111/1911-3846.12098

Francis, B., Hasan, I., Park, J. C., \& Wu, Q. (2015b). Gender Differences in Financial Reporting Decision Making: Evidence from Accounting Conservatism. Contemporary Accounting Research, 32(3), 1285-1318. https://doi.org/10.1111/1911-3846.12098

Francis, J., LaFond, R., Olsson, P., \& Schipper, K. (2005). The market pricing of accruals quality. Journal of Accounting and Economics, 39, 295-327. https://doi.org/10.1016/i.jacceco.2004.06.003

Gonçalves, T., Gaio, C., \& Santos, T. (2019). Women on the Board: Do They Manage Earnings? Empirical Evidence from European Listed Firms. Review of Business Management, 21(3), 585-597. https://doi.org/10.7819/rbgn.v21i3.4010

Grosvold, J., Brammer, S., \& Rayton, B. (2007). Board diversity in the United Kingdom and Norway: an exploratory analysis. Business Ethics: A European Review, 16(4), 344-357. https://doi.org/10.1111/j.14678608.2007.00508.x

Gul, F. A., Hutchinson, M. R., \& Lai, K. M. Y. (2013). Gender-Diverse Boards and Properties of Analyst Earnings Forecasts. Accounting Horizons, 27(3), 511-538. https://doi.org/10.2308/acch-50486

Gul, F. A., Srinidhi, B., \& Ng, A. C. (2011). Does board gender diversity improve the informativeness of stock prices? Journal of Accounting and Economics, 51(3), 314-338. https://doi.org/10.1016/i.jacceco.2011.01.005

Habib, A., \& Hossain, M. (2013). CEO/CFO characteristics and financial reporting quality: A review. Research in Accounting Regulation, 25(1), 88-100. https://doi.org/10.1016/j.racreg.2012.11.002

Healy, P. M., \& Wahlen, J. M. (1999). A Review of the Earnings Management Literature and Its Implications for Standard Setting. Accounting Horizons, 13(4), 365-383. https://doi.org/10.2308/acch.1999.13.4.365

Hili, W., \& Affes, H. (2012). Corporate boards gender diversity and earnings Persistence: The case of French listed firms. Global Journal of Management and Business Research, 12(22), 2249-4588. 
Hryniewicz, L. G. C., \& Vianna, M. A. (2018). Mulheres em posição de liderança: obstáculos e expectativas de gênero em cargos gerenciais. Cadernos EBAPE.BR, 16(3), 331-344. https://doi.org/10.1590/1679$\underline{395174876}$

Instituto Brasileiro de Governança Corporativa (IBGC). (2019). Apenas 10, 8\% das empresas do Ibovespa têm mulheres em conselhos. Disponível em: https://www.ibgc.org.br/blog/sep500-b3-mulheres

Ismail, I., Shafie, R., \& Ismail, K. N. I. K. (2020). Current Trends and Future Directions on Women CEOs/CFOs and Financial Reporting Quality. The Journal of Asian Finance, Economics and Business, 7(11), 679-687. https://doi.org/10.13106/jafeb.2020.vol7.no11.679

Jiang, J. X., Petroni, K. R., \& Wang, I. Y. (2010). CFOs and CEOs: Who have the most influence on earnings management? Journal of Financial Economics, 96(3), 513-526. https://doi.org/10.1016/i.jfineco.2010.02.007

Kim, H. A., Jeong, S. W., Kang, T., \& Lee, D. (2017). Does the Presence of Female Executives Curb Earnings Management? Evidence from Korea. Australian Accounting Review, 27(4), 494-506. https://doi.org/10.1111/auar.12169

Klenke, K. (2003). Gender influences in decision-making processes in top management teams. Management Decision, 41(10), 1024-1034. https://doi.org/10.1108/00251740310509553

Krishnan, G. V., \& Parsons, L. M. (2008). Getting to the bottom line: An exploration of gender and earnings quality. Journal of Business Ethics, 78(1-2), 65-76. https://doi.org/10.1007/s10551-006-9314-z

Liu, Y., Wei, Z., \& Xie, F. (2016). CFO gender and earnings management: Evidence from China. Review of Quantitative Finance and Accounting, 46(4), 881-905. https://doi.org/10.1007/s11156-014-0490-0

Loomis, C. J. (1999). The crackdown is here. Fortune, 53(9), 75-99.

https://doi.org/10.1017/CBO9781107415324.004

Lustosa, P. R. B., Fernandes, J. L. T., Nunes, D. M. S., \& Júnior, J. B. de A. (2010). Estimativas Contábeis e Qualidade do Lucro: Análise Setorial no Brasil. Revista de Educação e Pesquisa Em Contabilidade (REPEC), 4(2), 43-61. https://doi.org/10.17524/repec.v4i2.200

Mian, S. (2001). On the choice and replacement of chief financial officers. Journal of Financial Economics, 60(1), 143-175. https://doi.org/10.1016/S0304-405X(01)00042-3

$\mathrm{Na}, \mathrm{K} .$, \& Hong, J. (2017). CEO gender and earnings management. Journal of Applied Business Research, 33(2), 297-308. https://doi.org/10.19030/jabr.v33i2.9902

Natividad, I. (2011). Accelerating Board Diversity: an Update. Corporate Women Directors International.

Niederle, M., \& Vesterlund, L. (2007). Do women shy away from competition? Do men compete too much?. The Quarterly Journal of Economics, 122(3), 1067-1101. https://doi.org/10.1162/qjec.122.3.1067

Panzer, L., \& Müller, S. (2015). Earnings quality and gender diversity on German supervisory boards: An empirical analysis. Problems and Perspectives in Management, 13(4), 9-18. Disponível em:

https://businessperspectives.org/images/pdf/applications/publishing/templates/article/assets/6960/PPM 201 5 04 Panzer.pdf

Peni, E., \& Vähämaa, S. (2010). Female executives and earnings management. Managerial Finance, 36(7), 629-645. https://doi.org/10.1108/03074351011050343

Ray, D. M. (2005). Corporate Boards and Corporate Democracy. Journal of Corporate Citizenship, 20, 93105. https://doi.org/10.9774/gleaf.4700.2005.wi.00011

Schmiliver, A. L., Teixeira, M. S., Brandão, M. D., Andrade, V. D., \& Jucá, M. N. (2019). A presença de mulheres cria valor às empresas? Revista Pretexto, 20(3), 83-97.

https://doi.org/10.21714/pretexto.v20i3.6700

Segura, L. C., Formigoni, H., Abreu, R., \& Costa, R. G. (2016). A relação entre a presença de mulheres no conselho e o gerenciamento de resultados nas companhias abertas brasileiras. REDECA, 3(1), 106-119. 
Shawver, T., Bancroft, P., \& Sennetti, J. (2005). Can the "Clan Effect" Reduce the Gender Sensitivity to Fraud? The Case of the IPO Environment. Journal of Forensic Accounting, 11(2).

Silva, A. L. C. da, \& Margem, H. (2015). Mulheres em Cargos de Alta Administração Afetam o Valor e Desempenho das Empresas Brasileiras? Revista Brasileira de Finanças, 13(1), 102-133.

Silva Júnior, C. P. da, \& Martins, O. S. (2017). Mulheres no Conselho Afetam o Desempenho Financeiro? Uma Análise da Representação Feminina nas Empresas Listadas na BM\&FBOVESPA. Sociedade, Contabilidade e Gestão, 12(1), 62-76. https://doi.org/10.21446/scg ufri.v12i1.13398

Srinidhi, B., Gul, F. A., \& Tsui, J. (2011). Female directors and earnings quality. Contemporary Accounting Research, 28(5), 1610-1644. https://doi.org/10.1111/j.1911-3846.2011.01071.x

Terjesen, S., Aguilera, R. V., \& Lorenz, R. (2015). Legislating a Woman's Seat on the Board: Institutional Factors Driving Gender Quotas for Boards of Directors. Journal of Business Ethics, 128(2), 233-251. https://doi.org/10.1007/s10551-014-2083-1

Terjesen, S., Couto, E. B., \& Francisco, P. M. (2016). Does the presence of independent and female directors impact firm performance? A multi-country study of board diversity. Journal of Management and Governance, 20(3), 447-483. https://doi.org/10.1007/s10997-014-9307-8

Thiruvadi, S., \& Huang, H. W. (2011). Audit committee gender differences and earnings management. Gender in Management, 26(7), 483-498. https://doi.org/10.1108/17542411111175469

Wells, K. (2020). Who manages the firm matters: The incremental effect of individual managers on accounting quality. Accounting Review, 95(2), 365-384. https://doi.org/10.2308/accr-52505

Zalata, A. M., Ntim, C., Aboud, A., \& Gyapong, E. (2019). Female CEOs and Core Earnings Quality: New Evidence on the Ethics Versus Risk-Aversion Puzzle. Journal of Business Ethics, 160(2), 515-534. https://doi.org/10.1007/s10551-018-3918-y

\section{NOTAS}

\section{AGRADECIMENTOS}

Não se aplica

\section{CONTRIBUIÇÃO DE AUTORIA}

Concepção e elaboração do manuscrito: S. A. Fabrício, K. Dalcero, D. D. M. Ferreira, A. R. Mussoi

Coleta de dados: S. A. Fabrício, K. Dalcero, D. D. M. Ferreira, A. R. Mussoi

Análise de dados: K. Dalcero, S. A. Fabrício, D. D. M. Ferreira, A. R. Mussoi

Discussão dos resultados: K. Dalcero, S. A. Fabrício, D. D. M. Ferreira, A. R. Mussoi

\section{CONJUNTO DE DADOS DE PESQUISA}

Todo o conjunto de dados que dá suporte aos resultados deste estudo foi publicado no artigo e na seção "Materiais suplementares".

\section{FINANCIAMENTO}

Não se aplica

\section{CONSENTIMENTO DE USO DE IMAGEM}

Não se aplica.

\section{APROVAÇÃO DE COMITÊ DE ÉTICA EM PESQUISA \\ Não se aplica.}

\section{CONFLITO DE INTERESSES}

Não se aplica.

\section{LICENÇA DE USO}

Os Direitos Autorais para artigos publicados neste periódico são do autor, com direitos de primeira publicação para a Revista. Em virtude de aparecerem nesta Revista de acesso público, os artigos são de uso gratuito, com atribuições próprias, em aplicações educacionais, de exercício profissional e para gestão pública. A 
Revista adotou a licença Creative Commons Atribuição 4.0 Internacional - CC BY NC ND. Esta licença permite acessar, baixar (download), copiar, imprimir, compartilhar, reutilizar e distribuir os artigos desde que com a citação da fonte, atribuindo os devidos créditos de autoria. Nesses casos, nenhuma permissão é necessária por parte dos autores ou dos editores. Autores têm autorização para assumir contratos adicionais separadamente, para distribuição não-exclusiva da versão do trabalho publicada nesta revista (ex.: publicar em repositório institucional ou um capítulo de livro).

\section{PUBLISHER}

Universidade Federal de Santa Catarina. Curso de Ciências Contábeis e Programa de Pós-graduação em Contabilidade. Publicação no Portal de Periódicos UFSC. As ideias expressadas neste artigo são de responsabilidade de seus autores, não representando, necessariamente, a opinião dos editores ou da universidade.

\section{EDITORES}

Carlos Eduardo Facin Lavarda e Suliani Rover

\section{HISTÓRICO}

Recebido em: 21/08/2020 - Revisado por pares em: 20/10/2020 - Reformulado em: 20/12/2020 Recomendado para publicação em: 21/01/2021 - Publicado em: 22/03/2021 